\title{
Electroencephalogram (EEG) Features of Post-Stroke Seizure Patients in the Department of Neurology, Dr. Soetomo General Hospital Surabaya
}

\author{
Jessica Vania Wibowo ${ }^{\mathrm{a}}$, Kurnia Kusumastuti ${ }^{\mathrm{b} *}$, Rahadian Indarto Susilo ${ }^{\mathrm{c}}$ \\ ${ }^{a}$ Medical Study Program, Faculty of Medicine, University of Airlangga 60132, Surabaya, Indonesia \\ ${ }^{b}$ Department of Neurology, Dr. Soetomo General Hospital, University of Airlangga 60132, Surabaya, Indonesia \\ 'Department of Neurosurgery, Dr. Soetomo General Hospital, University of Airlangga 60132, Surabaya, Indonesia \\ *Corresponding Author: kurnia.kusumastuti@yahoo.com
}

\begin{abstract}
Backgrounds: Seizures are one of the most common and hazardous neurological complications of a stroke. Post-stroke seizures were classified as early-onset seizure and late-onset seizure, depending on seizure onset after stroke. Stroke is one of the most common risk factors for seizures and epilepsy, especially in older patients, accounting for 39-45\% of all seizure incidents. Knowledge of various risk factors and capability to perform supporting examinations such as EEG are essential to do with the aim of early detection, improving the prevention and treatment of post-stroke seizures so that it is expected to reduce the prevalence and mortality rate of post-stroke seizures.

Objectives: This study aims to determine the electroencephalogram (EEG) features found in post-stroke seizure patients in the Department of Neurology, Dr. Soetomo Surabaya Hospital

Methods: This study is a descriptive observational study using secondary data obtained from the medical records of patients with post-stroke seizures at the Department of Neurology, Dr. Soetomo Surabaya Hospital within the time period of January 2017 - December 2019.

Results: In this research, we evaluated seizure characteristics in 230 patients who had an ischemic and hemorrhagic stroke. 116 patients were male $(50.4 \%)$ while 114 patients were female $(49.6 \%)$. The highest age range found in the study sample was $>19-60$ years. In addition, this study revealed that $58.7 \%$ of seizures were focal seizures and $39.1 \%$ were generalized seizures, the remaining $2.2 \%$ were unknown seizures. Focal seizures become bilateral tonic-clonic seizures are the most common type of focal seizures while generalized tonic-clonic seizures are the most common type of generalized seizures seen. $80 \%$ of patients with focal seizures have impaired awareness during seizures. Seizures occurred in 148 ischemic stroke patients $(64.3 \%)$ and 82 hemorrhagic stroke patients $(35.7 \%)$. 97 Patients with ischemic stroke had thrombus etiology (65.5\%) and 32 had an embolic etiology (21.6\%), while patients with hemorrhagic stroke had the most dominant etiology, namely ICH as many as 53 patients (64.6\%). lesions were cortical (47.8\%) and 91 patients had lesions located subcortical (39.6\%). The majority of patients experienced early-onset seizures (55.2\%) and the majority of patients had EEG recordings $7-<14$ days and $3-<7$ days after seizure manifestations $(29.1 \%)$. EEG results showed abnormal features in $78.7 \%$ patients. Slow activity EEG is the most visible EEG picture with Continuous Slow Activity (CSA) as the most dominant pattern, while in epileptiform EEG the sharp/spike-wave image is the most common pattern. In the EEG special pattern, the most common picture is asymmetry decreased background rhythm accompanied by CSA. Conclusion: This hospital-based study showed that post-stroke seizures were associated with young and middle-aged (>19-60 years), male gender, ischemic stroke, thrombus type, cortical location, and comorbid hypertension, with a high prevalence rate in patients with hypertension. Based on this study, our data showed that patients with post-stroke seizures after stroke were more likely to have impaired awareness during the seizure. Most EEG features found in this study are continuous slow activity waves. In this study, post-stroke seizures occurred more commonly after ischemic stroke, middle-aged, and when the stroke occurred in the cortical region
\end{abstract}

Keywords: Stroke; Neurology; Seizures; Electroencephalography 


\section{Introduction}

Seizures can increase the morbidity and mortality of stroke patients [1]. In stroke patients, seizure activity can impede post-stroke recovery and cause temporary or even permanent neurologic impairment and it is associated with poor functional outcomes. The incidence of post-stroke seizures is certainly very dangerous, therefore treatment with Anti Epileptic Drugs (AED) is needed. Before administering an AED, the type of seizure that occurs in the patient must be diagnosed first. This is because AEDs can only treat certain types of seizures and cannot be used to treat other types of seizures. Administration of AEDs without a prior diagnosis can often worsen the patient's symptoms, and even increase morbidity [2]. In addition to the patient's clinical symptoms, supporting investigations can help to better understand the patient's seizure type [3]. One of the tools used in the investigation is an electroencephalogram (EEG). EEG is a non-invasive neurodiagnostic instrument that can detect abnormal changes in electrical activity in the brain [4]. Monitoring using poststroke EEG can increase the alertness of medical personnel, especially doctors, in predicting/detecting the risk of seizures in stroke patients by identifying a pattern of significant electrical activity against a lesion in the brain. EEG can detect early changes in brain electrical activity after stroke [5]. EEG can also be helpful in the early evaluation of poorly defined focal neurologic symptoms of post-stroke seizures [6]. Debicki (2017) also states that the presence of abnormalities in EEG (epileptiform waves or focal slowing) can predict seizure recurrence or recurrence [7]. Until now, research on EEG features and characteristics/risk factors of poststroke seizure patients has not been widely carried out in Indonesia, especially in Surabaya city.

Seizures are characterized by transient neurological signs or symptoms that cause the activity of neurons in the central nervous system to be abnormal, paroxysmal, and hypersynchronous in the cerebral cortex. Seizures can be caused by primary dysfunction of the central nervous system, one of the causes is stroke [8]. Stroke occurs in 16.9 million people every year and is the second leading cause of death in the world. $69 \%$ of the incidence of stroke occurs in low and middle income countries [9]. There are two main categories of brain damage in stroke patients, namely ischemic stroke and hemorrhagic stroke. Stroke is one of the most common risk factors for seizures and epilepsy, especially in the elderly patient group [10,11], accounting for $39-45 \%$ of all seizure incidents $[12,13]$. Patients who have a history of stroke will be very susceptible to seizures and epilepsy [14]. As the world population ages and the prevalence of stroke increases, the number of patients with post-stroke seizures is expected to increase [6]. Post-stroke seizures are also common in middle-aged patients and can occur after ischemic or hemorrhagic stroke [15]. Seizures are one of the most common and dangerous complications of a stroke, and approximately $10 \%$ of all stroke patients experience one or more seizures [16]. The prevalence of seizures is predicted to increase along with the increasing incidence of stroke [14].

Post-stroke seizures are categorized into 2 based on the onset of seizures after stroke, namely early-onset seizures and late-onset seizures. According to the definition of the International League Against Epilepsy, if seizures occur within 7 days after stroke it is classified as early-onset seizures and if seizures occur after more than 7 days after stroke the seizure is classified as late-onset seizures [17,6,18]. Early-onset seizures occur as a result of various pathophysiological mechanisms such as metabolic dysfunction, the abnormal release of excitotoxic neurotransmitters, and blood products of metabolism that irritate the cortex, whereas late-onset seizures tend to be caused by gliosis, loss of nervous tissue function, and hemosiderin deposits [19,11 20]. The prevalence of post-stroke seizures differs according to stroke subtype, lesion size, stroke location, and severity [21,13]. EEG can provide useful information for patients with structural brain diseases such as 
ischemic or hemorrhagic injuries [22]. The specific features found on the EEG have important implications for treatment because medical therapy varies for the different types of seizures seen in stroke patients. However, there are still many stroke patients who do not routinely check their EEG, this may happen because EEG is not accessible in all centers and the cost-benefit cannot be determined [23]. Whereas EEG examination greatly contributes to providing an accurate diagnosis and prognosis, so that stroke patients who are at risk of seizures get prompt and appropriate treatment guidelines.

Identifying risk factors in patients with post-stroke seizures is very important for appropriate therapeutic management. Knowledge of these various risk factors and capability in carrying out supporting examinations are very important to do with the aim of early diagnosis/detection, increasing prevention and treatment of post-stroke seizures so that it is expected to reduce the prevalence and mortality rate of post-stroke seizures [24]. Therefore, this study was conducted with the aim of providing data on EEG features in post-stroke seizure patients in the Department of Neurology, Dr. Soetomo Hospital. This study also provides data on the incidence and characteristics of stroke patients with seizures.

\section{Method}

This research is a descriptive observational study by observing secondary data obtained from the medical records of post-stroke seizure patients at the Department of Neurology, Dr. Soetomo Surabaya Hospital for the period January 2017 - December 2019. Our research was conducted from April 2020 to May 2021. The target population in this study were all patients diagnosed with post-stroke seizure manifestations who were treated at the Department of Neurology, Dr. Soetomo Surabaya Hospital in the period January 2017 December 2019. To determine the population to be used as the research sample, screening was applied with inclusion and exclusion criteria. The inclusion criteria for this study were patients with post-stroke seizures who were diagnosed clinically and radiologically at the Department of Neurology, Dr. Soetomo Surabaya Hospital in the period January 2017 - December 2019 and the patient's medical record data included the diagnosis of the EEG examination. The exclusion criteria in this study were incomplete patient medical records or did not include the variables to be studied. The research sample used was post-stroke seizure patients who were being treated at Dr. Soetomo Surabaya Hospital and patient data were recorded in the patient's medical record in the period January 2017 - December 2019 and met the inclusion criteria in the target population. The sampling technique used in this research is to use the total sampling method. The variables of this study included gender, age, seizure type based on the onset, awareness of focal seizures, stroke type, stroke location, seizure type based on the post-stroke onset, the time interval between last seizure and EEG recording, EEG recording results, risk factors/comorbidities of patients. The collected data variables will be identified based on inclusion and exclusion criteria, then processed using SPSS software and presented descriptively in the form of tables and narratives. This research has received ethical approval from the Ethics Commission of Dr. Soetomo General Hospital Surabaya.

\section{Result}

There are 310 patient medical records registered in the Department of Neurology RSUD Dr. Soetomo Surabaya in the period January 2017 to December 2019. Of the 310 medical records, 80 patients were excluded because the patient's medical records had incomplete data so that the total number of patients who entered the inclusion criteria was 230 patients. Patient characteristics are shown in Table 1. 
Table 1. Characteristics of Research Subjects

\begin{tabular}{|c|c|c|}
\hline Variable & & $\mathrm{n}(\%)$ \\
\hline \multirow[t]{2}{*}{ Gender } & Man & $116(50.4)$ \\
\hline & Woman & $114(49.6)$ \\
\hline \multirow[t]{5}{*}{ Age } & $0-1$ years old & $1(0.4)$ \\
\hline & $>1-10$ years old & $4(1.7)$ \\
\hline & $>10-19$ years old & $9(3.9)$ \\
\hline & > 19-60 years old & $135(58.7)$ \\
\hline & $>60$ years old & $81(35.2)$ \\
\hline \multirow[t]{3}{*}{ Types of seizures based on onset } & Focal & $135(58.7)$ \\
\hline & Generalized & $90(39.1)$ \\
\hline & Unknown & $5(2,2)$ \\
\hline \multirow[t]{6}{*}{ Focal seizure sub-type } & Focal to bilateral tonic-clonic & $78(57.8)$ \\
\hline & Focal tonic & $11(8,1)$ \\
\hline & Focal clonic & $14(10,4)$ \\
\hline & Focal to bilateral tonic & $5(3,7)$ \\
\hline & Focal to bilateral clonic & $6(4,4)$ \\
\hline & Focal tonic-clonic & $21(15.6)$ \\
\hline \multirow[t]{2}{*}{ Awareness during focal seizures } & Impaired awareness & $108(80.0)$ \\
\hline & Aware & $27(20,0)$ \\
\hline \multirow[t]{3}{*}{ Generalized seizure sub-type } & General tonic & $21(23.3)$ \\
\hline & General clonic & $10(11,1)$ \\
\hline & General tonic-clonic & $59(65.6)$ \\
\hline \multirow[t]{2}{*}{ Stroke classification } & Ischemic & $148(64.3)$ \\
\hline & Hemorrhagic & $82(35.7)$ \\
\hline \multirow[t]{3}{*}{ Ischemic stroke type } & Embolism & $32(21.6)$ \\
\hline & Thrombus & $97(65.6)$ \\
\hline & Thromboembolism & $19(12.8)$ \\
\hline \multirow[t]{7}{*}{ Hemorrhagic stroke type } & $\mathrm{SAH}$ & $8(9.8)$ \\
\hline & $\mathrm{ICH}$ & $53(64.6)$ \\
\hline & SAH with IVH & $3(3,7)$ \\
\hline & ICH with SAH & $7(8.5)$ \\
\hline & ICH with IVH & $7(8.5)$ \\
\hline & ICH with SDH & $1(1,2)$ \\
\hline & ICH with IVH and SAH & $3(3,7)$ \\
\hline \multirow[t]{3}{*}{ Location of stroke } & Cortical & $110(47.8)$ \\
\hline & Subcortical & $91(39.6)$ \\
\hline & Cortical and Subcortical & $29(12.6)$ \\
\hline \multirow{2}{*}{$\begin{array}{l}\text { Seizure types based on post-stroke } \\
\text { onset }\end{array}$} & Early-onset seizures & $127(55.2)$ \\
\hline & Late-onset seizures & $103(44.8)$ \\
\hline \multirow{4}{*}{$\begin{array}{l}\text { Time interval between last seizure } \\
\text { and EEG recording }\end{array}$} & $<24$ hours & $3(1,3)$ \\
\hline & $1-<3$ days & $37(16.1)$ \\
\hline & $3-<7$ days & $67(29.1)$ \\
\hline & $7-<14$ days & $67(29.1)$ \\
\hline
\end{tabular}




$\begin{array}{ll}14-<21 \text { days } & 30(13.0) \\ 21-<30 \text { days } & 15(6.5) \\ >30 \text { hours } & 11(4.8)\end{array}$

Based on medical record data, most cases of post-stroke seizures occurred in 116 patients $(50.4 \%)$ male and 114 patients $(49.6 \%)$ female. In this study, there were 135 patients $(58.7 \%)$ with post-stroke seizures who were $>19-60$ years old. From the overall data, the youngest age was 1 year old and the oldest was 87 years old.

On examination, 135 patients $(58.7 \%)$ had focal seizures, 90 patients $(39.1 \%)$ had generalized seizures, and 5 patients $(2.2 \%)$ had unknown onset seizures. The most common type of seizure found was focal onset seizures to bilateral tonic-clonic seizures. 78 out of 135 patients with focal seizures had focal to bilateral tonic-clonic seizures, 59 patients out of 90 patients with generalized seizures had generalized tonic-clonic seizures. 108 patients with focal seizures had impaired awareness during seizures (80.0\%), and 27 patients experienced awareness during seizures (20.0\%). 59 patients out of 90 patients with generalized seizures had generalized tonic-clonic seizures $(65.6 \%), 21$ patients had generalized tonic seizures $(23.3 \%)$, and 10 patients had generalized clonic seizures (11.1\%). Early-onset seizures were seen in 127 patients (55.2\%), whereas 103 patients $(44.8 \%)$ had late-onset seizures.

148 patients out of 230 patients had an ischemic stroke $(64.3 \%)$ while hemorrhagic stroke was seen in 82 patients $(35.7 \%)$. The most common type of ischemic stroke based on the etiology in this study was thrombus ischemic stroke in 97 patients $(65.5 \%)$, followed by an embolic ischemic stroke in 32 patients $(21.6 \%)$, and thromboembolic ischemic stroke in 19 patients $(12,8 \%)$. Meanwhile, in hemorrhagic stroke, the majority etiology was ICH stroke (64.6\%). 110 out of 230 post-stroke seizure patients had a stroke location in the cortical (47.8\%), 91 patients had a stroke location in the subcortical (39.6\%), and as many as 29 patients had a stroke location in the cortical and subcortical (12.6\%).

Table 2. Electroencephalogram characteristics of post-stroke seizure patients

\begin{tabular}{lll}
\hline \multicolumn{1}{c}{ Variable } & & $\mathrm{n}(\%)$ \\
\hline Types of EEG images & Normal & $49(21.3)$ \\
& Abnormal & $181(78.7)$ \\
Abnormal EEG classification & Slow Activity & $169(70.4)$ \\
& Special Pattern & $17(7.1)$ \\
& Epileptiform & $54(22.5)$ \\
Number of Epileptiform EEG Features & 1 Epileptiform EEG feature & $50(92.6)$ \\
Seen in Patients & & $4(7,4)$ \\
Epileptiform EEG features & 2 Epileptiform EEG features & $9(15.5)$ \\
& EEG seizures & $47(81.0)$ \\
Epileptiform EEG features in focal & Sharp/spike-waves & $2(3,4)$ \\
seizures & SSWC & $30(78.9)$ \\
& Sharp/spike-waves & $7(18.4)$ \\
Epileptiform EEG features in & & $1(2.6)$ \\
generalized seizures & EEG seizures & $17(85.0)$
\end{tabular}




\begin{tabular}{|c|c|c|}
\hline \multirow{4}{*}{$\begin{array}{l}\text { Number of Slow Activity EEG Features } \\
\text { Seen in Patients }\end{array}$} & $\begin{array}{l}\text { EEG seizures } \\
\text { SSWC }\end{array}$ & $\begin{array}{l}2(10.0) \\
1(5.0)\end{array}$ \\
\hline & 1 Slow Activity EEG feature & $130(76.9)$ \\
\hline & 2 Slow Activity EEG features & $38(22.5)$ \\
\hline & 3 Slow Activity EEG features & $1(0.6)$ \\
\hline \multirow[t]{3}{*}{ Slow Activity EEG features } & BSA & $36(17.2)$ \\
\hline & CSA & $114(54.5)$ \\
\hline & ISA & $59(28.2)$ \\
\hline \multirow{2}{*}{$\begin{array}{l}\text { Slow Activity EEG features in Focal } \\
\text { Seizures }\end{array}$} & BSA & $24(18.0)$ \\
\hline & $\begin{array}{l}\text { CSA } \\
\text { ISA }\end{array}$ & $\begin{array}{l}69(51.9) \\
40(30.1)\end{array}$ \\
\hline \multirow[t]{2}{*}{$\begin{array}{l}\text { Slow Activity EEG features in } \\
\text { Generalized Seizures }\end{array}$} & BSA & $12(15.8)$ \\
\hline & $\begin{array}{l}\text { CSA } \\
\text { ISA }\end{array}$ & $\begin{array}{l}45(59.2) \\
19(25,0)\end{array}$ \\
\hline $\begin{array}{l}\text { Number of Special Pattern EEG Features } \\
\text { Seen in Patients }\end{array}$ & 1 Special Pattern EEG feature & $16(94.1)$ \\
\hline \multirow[b]{2}{*}{ EEG Special Pattern features } & 2 Special Pattern EEG features & $1(5,9)$ \\
\hline & $\begin{array}{l}\text { Asymmetry decreased background } \\
\text { rhythm }\end{array}$ & $8(44.4)$ \\
\hline \multirow{9}{*}{$\begin{array}{l}\text { Special Patterns EEG features in Focal } \\
\text { Seizures }\end{array}$} & Breach rhythm & $2(11,1)$ \\
\hline & Burst suppression & $2(11,1)$ \\
\hline & GPDs & $1(5.6)$ \\
\hline & PLEDs & $4(22.2)$ \\
\hline & Triphasic wave & $1(5.6)$ \\
\hline & Breach rhythm & $2(20,0)$ \\
\hline & PLEDs & $2(20,0)$ \\
\hline & Burst suppression & $1(10,0)$ \\
\hline & $\begin{array}{l}\text { Asymmetry decreased background } \\
\text { rhythm }\end{array}$ & $5(50.0)$ \\
\hline \multirow[t]{5}{*}{$\begin{array}{l}\text { Special Pattern EEG features in } \\
\text { Generalized Seizures }\end{array}$} & PLEDs & $2(25,0)$ \\
\hline & Burst suppression & $1(12,5)$ \\
\hline & $\begin{array}{l}\text { Asymmetry decreased background } \\
\text { rhythm }\end{array}$ & $3(37.5)$ \\
\hline & GPDs & $1(12,5)$ \\
\hline & Triphasic wave & $1(12,5)$ \\
\hline
\end{tabular}

Table 2 shows the characteristics of electroencephalogram in post-stroke seizure patients. The time interval from seizure manifestations to EEG recording of post-stroke seizure patients in this study was mostly done $7-<14$ and $3-<7$ days after the seizure, as many as 67 people (29.1\%). A total of 49 patients out of 230 patients had normal EEG results $(21.3 \%)$ and 181 patients had abnormal EEG findings (78.7\%). 169 patients had a slow activity EEG pattern (70.4\%), 54 patients had an epileptiform EEG pattern (22.5\%), and 17 patients had a special pattern EEG $(7.1 \%)$.

Of the 54 patients with epileptiform EEG features, 50 patients had 1 epileptiform EEG pattern $(92.6 \%)$, 
and 4 patients had 2 epileptiform EEG patterns (7.4\%). There were 47 patients with epileptiform sharp/spikewave EEG (81.0\%), 9 patients with seizure EEG pattern (15.5\%), 2 patients with SSWC EEG pattern (3.4\%). 30 patients with focal seizures had epileptiform sharp/spike-wave EEG features (78.9\%), 7 patients with focal seizures had EEG seizures pattern (18.4\%), and 1 patient had focal seizures with SSWC EEG pattern (2.6\%). While 17 generalized seizure patients had sharp/spike-wave epileptiform EEG images (85.0\%), 2 generalized seizure patients had EEG seizures pattern $(10.0 \%)$, and 1 generalized seizure patient had SSWC EEG pattern (5.0\%). Of the 169 patients with slow activity features, there were 130 patients with 1 slow activity EEG pattern (76.9\%), 38 patients with 2 slow activity EEG patterns (22.5\%), and 1 patient with 3 slow activity EEG patterns $(0.6 \%)$. There were 114 patients with CSA slow activity EEG pattern (54.5\%), 59 patients with ISA slow activity EEG pattern (28.2\%), 36 patients with BSA slow activity EEG pattern (17.2\%). A total of 69 focal seizure patients had CSA slow activity EEG pattern (51.9\%). 40 focal seizure patients had ISA slow activity EEG pattern (30.1\%), 24 focal seizure patients had BSA slow activity EEG pattern (18.0\%). Meanwhile, 45 patients with generalized seizures had a CSA slow activity EEG pattern (59.2\%), 19 patients with generalized seizures had an ISA slow activity EEG pattern $(25.0 \%)$, and 12 patients with generalized seizures had a picture of a BSA slow activity EEG pattern (15.8\%). Of the 17 patients with special EEG patterns, 16 patients had 1 special pattern EEG feature (94.1\%), and 1 patient had 2 special pattern EEG features $(5.9 \%)$. There were 8 patients with asymmetry decreased background rhythm patterns with the highest percentage (44.4\%). 5 focal seizure patients had asymmetry decreased background rhythm patterns $(50.0 \%)$. Meanwhile, there were 3 generalized seizure patients with asymmetry decreased background rhythm pattern with the highest percentage (37.5\%).

Table 3. Distribution of Risk Factors/Comorbid Post-Stroke Seizure Patients

\begin{tabular}{ll}
\hline Risk factors/comorbid & $\mathrm{n}(\%)$ \\
\hline Hypertension & $81(33.1)$ \\
Diabetes Mellitus & $57(23.3)$ \\
Cardiovascular disease & $24(9.8)$ \\
Head trauma & $15(6.1)$ \\
CKD & $14(5.7)$ \\
Pneumonia (CAP, HAP) & $11(4.5)$ \\
Aneurysm & $9(3.7)$ \\
Tumor & $8(3,3)$ \\
Acute Kidney Injury & $8(3,3)$ \\
Dyslipidemia & $6(2,4)$ \\
Arteriovenous malformations & $4(1.6)$ \\
\hline
\end{tabular}

Table 3 shows the distribution of risk factors/comorbidities in post-stroke seizure patients in the Department of Neurology, Dr. Soetomo General Hospital Surabaya. The most common risk factor found in post-stroke seizure patients was hypertension, there were 81 patients $(33.1 \%)$ with hypertension, 57 patients (23.3\%) with diabetes mellitus, 24 patients $(9.8 \%)$ with cardiovascular disease. In the present study, both early-onset and late-onset seizures were found to be more common in patients with cortical than in subcortical lesions and in patients with ischemic stroke than in patients with hemorrhagic stroke (Table 4). In this study, a higher incidence of ischemic stroke and hemorrhagic stroke was found in the cortical than in the subcortical 
region (Table 5).

Table 4. Distribution of stroke type and stroke location in early-onset and late-onset seizures

\begin{tabular}{|c|c|c|}
\hline Parameter & Early-onset seizures & Late-onset seizures \\
\hline Stroke type & $\mathrm{n}(\%)$ & $\mathrm{n}(\%)$ \\
\hline - Ischemic & $80(54.1)$ & $68(45.9)$ \\
\hline - Hemorrhagic & $47(57.3)$ & $35(42.7)$ \\
\hline \multicolumn{3}{|l|}{ Location of stroke } \\
\hline - $\quad$ Cortical & $62(56.4)$ & $48(43.6)$ \\
\hline - Subcortical & $47(51.6)$ & $44(48.4)$ \\
\hline $\begin{array}{l}\text { - Cortical and } \\
\text { subcortical }\end{array}$ & $18(62.1)$ & $11(37.9)$ \\
\hline
\end{tabular}

Table 5. Distribution of Stroke Types and Stroke Locations

\begin{tabular}{lccc}
\hline \multicolumn{1}{c}{ Parameter } & Cortical & Subcortical & Cortical and Subcortical \\
\hline Stroke Type & $\mathrm{n}(\%)$ & $\mathrm{n}(\%)$ & $\mathrm{n}(\%)$ \\
\hline Ischemic & $66(44.6)$ & $65(43.9)$ & $17(11.5)$ \\
Hemorrhagic & $44(53.7)$ & $26(31.7)$ & $12(14.6)$ \\
\hline
\end{tabular}

\section{Discussion}

In this study, post-stroke seizures were more common in male patients than female patients. This is consistent with the results of several studies which state male dominance in the incidence of post-stroke seizures [1,12,15,16,21,26,27]. However, a study by Misirli et al, (2006) showed that gender was not an important and significant risk factor for the onset of seizures [28]. There is no significant difference between the seizure ratio in men and women with stroke, in other words, both genders have the same risk of poststroke seizures [10,17,29,30,31]. A meta-analysis study that included studies published in 1990-2014, found no significant difference in episodes of early-onset and late-onset seizures between male and female patients [18]. This statement is also consistent with the results of a study by Mehta et al, (2018) where gender has no influence on the occurrence of early-onset or late-onset seizures [15]. The study conducted in Indonesia also stated that the comparison of the number of post-stroke seizure patients who were male and female was not much different and the percentage of stroke incidence in male patients was slightly higher than in female [14].

In this study, the highest age prevalence of post-stroke seizure patients was patients with an age range > 19-60 years, followed by patients with an age range $>60$ years. These results are in accordance with research conducted by Misirli, et al (2006), Mehta, et al (2018), and Xu, M.Y (2019), which stated that patients with age $<65$ years (middle-aged) had a risk for the development of post-stroke seizures and the study reported a higher incidence of seizures at this age [15,28,32]. The study by Feyissa, et al (2019) also stated that poststroke epilepsy was more frequently reported in patients aged $<65$ years than in patients aged $>85$ years [6]. 
The results of this study are also in accordance with research conducted by Conrad, et al (2013), where in this study the average age of patients with post-stroke seizures was $56.6 \pm 16.5$ years old, the mean age of stroke cases with early-onset seizures was 53.9. \pm 18.7 years old and the mean age of stroke cases with late-onset seizures was $59.0 \pm 14.1$ years old [12]. Research conducted in Indonesia by Tombeng, et al (2020) found that the highest prevalence of post-stroke seizures was in patients aged 45-54 years followed by patients aged 5564 years [14]. Misirli, et al (2006) provide an explanation for this, that epileptogenicity is generally weaker in the brains of older people compared to the brains of young people [28]. This statement is in accordance with the explanation by Conrad et al, (2013) that the aging brain will experience degenerative and neuroplastic changes that cause a decrease in the excitability of the brain cortex. Given that cortical gray matter volume is higher in younger patients, it can be assumed that younger patients experience seizures more frequently [12]. However, according to Alberti, et al (2008), Zhang, et al (2014), Kamble, et al (2017), and Mehta, et al (2018), age and gender have no effect on the occurrence of early-onset seizures and late-onset seizures in stroke patients and there was no statistically significant difference in the incidence of early-onset seizures compared with late-onset seizures in younger and older patients [15,18,25,30]. While Bladin, et al (2008), Burneo, et al (2010), Guekht and Bornstein (2012) did not find a significant difference between the incidence of post-stroke seizures with age [17,29,33].

This study classifies seizure types based on the 2017 ILAE criteria. The results of this study showed that more patients with focal seizures than generalized seizures. This supports the statement from several studies that report the incidence of focal seizures with or without generalization and with or without impaired awareness is more dominant than generalized seizures [1,19,29,32,34,35]. Chemer and Shevchenko (2021) stated that the prevalence of post-stroke seizures is mostly due to focal lesions, and post-stroke seizures are usually of focal onset [36]. This finding differs from several previous studies which stated a higher incidence of generalized seizures in post-stroke seizure patients [12,15,16,21,25,26,37]. Misirli, et al (2006) explained that the difference in outcome may occur because we might ignore the partial-onset of generalized seizures according to the patient's family history [28]. Kamble, et al (2017) and Mehta, et al (2018) also explain, the possible difference in the results of this study may be related to the low educational status of the study population group that could not report focal seizures or focal seizures to be bilateral and incorrect. interpreted it as a generalized seizure [15,25]. According to a study by Varelas, et al (2017), most post-stroke seizures have a focal onset. However, the facts in the field illustrate that it is difficult to distinguish between generalized seizures or focal seizures that become clinically bilateral unless the onset is witnessed or monitored using continuous video-EEG monitoring [34]. According to Bladin, et al (2008), data on seizure subtypes (focal to bilateral seizures, or generalized seizures) in post-stroke seizure studies are limited by the retrospective design of most studies, and the potential for error or recall bias is related to obtaining seizure descriptions from patients or bystanders [29]. Studies show that up to $63 \%$ of seizures may be unrecognized by patients. Therefore, it is not surprising that different studies found different frequencies of post-stroke seizure subtypes [37].

In this study, the most common form of focal seizures became bilateral tonic-clonic seizures, and generalized tonic-clonic seizures were found to have the highest prevalence. This finding is in accordance with the studies conducted by Okuda, et al (2012) and Feyissa, et al (2019). These studies explained that the most common form of seizures was focal to bilateral tonic-clonic seizures [6,27]

In this study, it was found that more patients had focal onset seizures with impaired consciousness than without impaired consciousness. This finding is also in accordance with a study conducted in Indonesia by 
Tombeng et al (2020). They found a predominance of focal onset seizures with impaired consciousness over focal seizures without impaired consciousness [14]. According to Feyissa, et al (2019), seizures can manifest with or without impaired consciousness with motor or non-motor symptoms depending on the location and size of the stroke [6]. However, this finding differs from several other studies which state that focal seizures without impaired consciousness have a higher incidence [25,34].

This study classified stroke using the 2016 Caplan criteria [46]. In this study, seizures tended to be more common in patients with ischemic stroke than hemorrhagic stroke. These results are consistent with several studies which state that the prevalence of ischemic stroke is higher than that of hemorrhagic stroke $[5,12,15,16,21,25,26,27,30,33,38,39]$. The etiology of stroke due to infarction is significantly more dominant than bleeding so that the main prevalence of seizures is related to the cerebral vascular occlusive disease. The incidence of seizures in hemorrhagic stroke or ischemic stroke varies from one study to another. Several previous studies have revealed a higher incidence of seizures in patients with hemorrhagic stroke than ischemic stroke $[10,29,32]$. The variability in study results could be due to variations in sample selection. Kamble, et al (2017) and Mehta, et al (2018) also explained that this may be because the ischemic stroke has a higher incidence than hemorrhagic stroke [15,25]. Although various stroke subtypes, both ischemic stroke and hemorrhagic stroke, are widely associated with an increased risk of seizures, a higher incidence of seizures has been reported in hemorrhagic stroke compared to ischemic stroke [10]. However, it is important to note that the frequency of ischemic stroke is much greater so the overall seizure burden may be higher in this group $[19,40]$. There are several studies that did not find a correlation between the incidence of seizures and the type of stroke. According to Misirli, et al (2006), there is no significant difference between stroke subtypes and the incidence of post-stroke seizures [28]. The results of this study are also in accordance with the results of research conducted in Indonesia by Tombeng, et al (2020). The study stated that the difference in the results of studies with some literature is thought to be caused by risk factors that increase the prevalence of post-stroke seizures, not only the type of stroke but also the severity of a stroke, location of the lesion, vascular risk factors, and genetic factors [14].

In this study, there were more patients with thrombus ischemic stroke etiology than embolic and thromboembolic ischemic strokes. This is in accordance with several studies which state that the prevalence of ischemic stroke with thrombus etiology is higher than ischemic stroke with embolic [16,21,30,39]. However, there are other studies that say otherwise [29,37]. There are also several studies that state that there is no relationship between the etiology of ischemic stroke and the incidence of seizures [28]. The type of thrombus ischemic stroke is not an important risk factor in the development of seizures. According to the results of this study, seizures were more common in the thrombotic ischemic stroke compared to the embolic subtype. This may be due to the high prevalence rate of thrombotic stroke cases compared to embolic subtypes in ischemic stroke patients in Dr. Soetomo Surabaya Hospital [16].

In this study, patients with the etiology of intracerebral hemorrhagic stroke (ICH) had a higher prevalence than other types of hemorrhagic stroke. This is in accordance with several studies which state that the prevalence of intracerebral hemorrhagic stroke $(\mathrm{ICH})$ is more common than other types of hemorrhagic stroke etiologies $[19,21,38,39]$. The location of the stroke lesion in cortical or subcortical was obtained based on the CT scan readings written in the medical record. The results of this study showed that patients with cortical lesions were more common than subcortical lesions and cortico-subcortical lesions. This is consistent with several studies which state that the prevalence of seizures in cortical lesions is higher than in subcortical lesions [5,6,10,12,18,19,21,25,27,29,30]. According to Misirli et al, (2006), cortical lesions are a major risk 
factor for the development of seizures in ischemic stroke and hemorrhagic stroke, in other words, people are more likely to have post-stroke seizures with cortical lesions [28]. The Seizures After Stroke Study (SASS) reported a twofold increase in the risk of seizures in stroke patients with lesions in the cortical regions. This statement is also supported by a study by Bladin, et al (2008) which stated that the risk factor for seizures after ischemic stroke and hemorrhagic stroke is cortical involvement [29]. According to a study conducted in Pakistan, strokes with a cortical location were more frequently associated with post-stroke seizures. It increases the risk of seizures almost fourfold compared to stroke in subcortical lesions. Cortical irritation is thought to be the cause of the higher epileptogenicity of stroke [31].

In this study, there were more patients with early-onset seizures than late-onset seizures. This is in accordance with several studies which state that stroke patients with early-onset seizures are more common $[21,25,26,39]$. However, there are several studies showing the prevalence of late-onset seizures is higher than that of early-onset seizures $[12,16,28,41]$. The variability in reported incidence between studies may be due to differences in definitions or the time limit used to categorize patients [32,39]. In addition, several research studies defined a different cut-off time variable for classifying seizures based on the time of occurrence after stroke. According to a study conducted by Doria, et al (2019), the most commonly used cut-off time is 7 days or 14 days to determine early-onset and late-onset seizures [19]. In addition, several studies exist that define early-onset seizures with various cutoff times, such as within 24-48 hours, 1 week, and 2 weeks after stroke and late-onset seizures with cutoff points of more than 1 week or occurring at least 2 weeks after stroke $[5,39,41]$.

In this study, the results of the distribution of time from seizure manifestation to EEG recording were found that the most frequently performed were $7-<14$ days and $3-<7$ days after seizure manifestation. The distance between the last seizure and the EEG examination may have an influence on the occurrence of epileptiform waves (which is the most dominant factor in the occurrence of epileptiform waves). Standard EEG examination is recommended to be performed within 24 hours of the last seizure [42]. The closer the distance between the seizure event and the recording, the more likely the EEG can still record the epileptic process in the brain. There was a study that found epileptiform waves in $51 \%$ of subjects who had an EEG within 24 hours and $34 \%$ of those who had an EEG thereafter [42]. There is also a study that found a seizure proportion of $89 \%$ in subjects who had an EEG within 24 hours of the seizure and none of the subjects had an epileptiform wave after 72 hours [43]. So it is recommended that an EEG should be performed within 24 hours because it is more useful in diagnosing abnormal epileptiform waves than an EEG performed $>24$ hours.

This study provides an overview of the most common EEG waves found in stroke patients with seizures. Most of the EEG features in post-stroke seizure patients in this study were abnormal EEGs. In this study, it was found that slow activity EEG was the most common type found in patients, followed by epileptiform EEG waves and special patterns. In this study, the slowing CSA (continuous slow activity) EEG form was relatively more dominant than other slow activity EEG forms. In the epileptiform wave, it was found that the Sharp/spike-wave EEG is relatively more dominant than other epileptiform EEG forms. In the special pattern EEG wave, it was found that the form of EEG asymmetry decreased background rhythm was relatively more dominant than other forms of EEG special pattern. This finding is in accordance with the research conducted by De Reuck, et al (2006); Chung, et al (2014); Varelas, et al (2017); and Mecarelli, et al (2011) who found that slowing waves were the most common EEG waves found in stroke patients with seizures [1,34,41]. Chemer et al., (2021) also suggested that focal slowing and diffuse slowing were found in $84 \%$ of patients 
[36]. This statement is reinforced by a study by Feyissa, et al (2019) which stated that the most frequent EEG findings in acute stroke were focal slowing EEG images according to the side of the infarct and diffuse slowing [6]. Wave reactivity can be used as an indicator to determine the extent of the damage. Changes in the EEG pattern in stroke patients with seizures are not specific, but if present they tend to be focal slowing. Patients with cerebral ischemia most often have slowing, loss of normal background activity, and a reduction in overall amplitude. Patients with post-intracerebral hemorrhage also experience focal slowing [29]. De Reuck, et al (2006) suggested that PLEDs are more common in early post-stroke seizures [1]. PLEDs are also frequently seen on the EEG of patients with cortical and focal seizures [29]. Interictal epileptiform abnormalities generally represent focal cortical irritation [41].

According to Lüders, H. and Noachtar, S (2000) sharp wave and spike-wave patterns are relatively typical and significant features of epilepsy, and there is no difference in diagnostic information between sharp waves and spike-waves [44]. Apart from their morphology, sharp waves and spike-waves have the same etiology and clinical significance in the evaluation of patients with epilepsy. According to Jaya et al (2018), the difference between sharp waves and spike-waves is only in their duration, where the spike-wave duration is 20-70 ms while the sharp wave duration is 70-200 ms [45].

In this study, the most epileptiform EEG images in focal and generalized seizures were sharp/spike-wave patterns. The most common slow activity EEG in focal and generalized seizures is CSA. The most common EEG special pattern in focal and generalized seizures is the asymmetry decreased background rhythm pattern. Hypertension is a comorbid disease and the most common risk factor found in stroke patients with seizures followed by diabetes mellitus, heart disease, and hyperlipidemia $[5,12,20,21,26,30,35]$. Patients with a history of heart disease and hypertension were also reported to have a strong association with the occurrence of poststroke seizures in the study by Kamble, et al (2017) [25]. According to Procaccianti, et al (2012) ischemic and hemorrhagic stroke showed no difference in risk factors, with the exception of coronary artery disease, atrial fibrillation, and smoking habits, which were significantly more representative of ischemic stroke [20].

In the present study, both early-onset and late-onset seizures were more common in patients with cortical than subcortical lesions. This statement is supported by previous studies which stated that the greatest risk factors for both types of seizures based on the onset, early-onset seizures and late-onset seizures, were cortical involvement and ischemic stroke [10,15,25,26,30,37,39]. a study by Okuda, et al (2012) reported that patients with cortical lesions and ischemic lesions had a much greater risk of late-onset seizures than subcortical lesions and hemorrhagic lesions [27]. The type of ischemic lesion and the location of the cortical lesion is also directly related to the risk of early-onset seizures [35].

In this study, it was found that the incidence of ischemic stroke and hemorrhagic stroke was higher in the cortical region than in the subcortical region. This statement is supported by previous studies which found that the prevalence of ischemic stroke and hemorrhagic stroke was higher in cortical than in subcortical [21,35]. According to Guekht and Bornstein (2012), hemorrhagic stroke patients have a 3 times higher risk of seizures if they are located in the cortical area [17]. This statement is supported by Doria and Forgacs (2019) who stated that the risk of hemorrhagic poststroke seizures was higher in cortical lesions [19].

\section{Conclusions}

Stroke is the most frequently identified cause in most patients with symptomatic seizures. This hospitalbased study showed that post-stroke seizures were associated with young and middle-aged (>19-60 years), male gender, ischemic stroke, thrombus type, cortical location, and comorbid hypertension, with a high 
prevalence rate in patients with hypertension. These findings are useful in the risk stratification of patients with stroke and may help to inform patients and clinicians about the risk of future seizures

In the case of post-stroke seizures, patients with focal seizures were more often aware of the duration of the seizure, but in this study, patients with post-stroke seizures were more likely to experience impaired awareness during seizures. Most EEG features found in this study are continuous slow activity waves.

The limitations of this study are the research design is limited to descriptive observational research, this study was only conducted in one place so that the description of the incidence of stroke with seizures was less extensive and varied and the medical record data incomplete so that not all patients could obtain clinical data. Another limitation of this study is the lack of analysis of the effects of post-stroke seizures on other outcomes such as infarct size and impaired functional recovery. It is recommended that an EEG should be performed within 24 hours of the last seizure because it is more useful in diagnosing abnormal epileptiform waves than an EEG performed $>24$ hours.

\section{Acknowledgements}

The author would like to thank the director of the Dr. Soetomo General Hospital Surabaya and the Department of Neurology Dr. Soetomo General Hospital Surabaya who has given permission and has supported this research. 


\section{References}

[1] De Reuck, J., Goethals, M., Claeys, I., Van Maele, G.E.O.R.G.E.S. and De Clerck, M., 2006. EEG findings after a cerebral territorial infarct in patients who develop early-and late-onset seizures. European neurology, 55(4), pp.209-213.

[2] Epilepsy Foundation, 2016, Retrieved: Agustus 19, 2020, from https://www.epilepsy.com/article/2014/3/why-classification-important

[3] Fisher, RS, Cross, JH, D’Souza, C, French, JA, Haut, SR, Higurashi, N, Hirsch, E, Jansen, FE, Lagae, L, Moshe, SL, Peltola, J, Roulet Perez, E, Scheffer, IE, Schulze Bonhage, A, Somerville, E, Sperling, M, Yacubian, EM, Zuberi, SM, 2017, 'Instruction manual for the ILAE 2017 operational classification of seizure types', Epilepsia, vol 58, pp 531, 542.

[4] Waxman, S.G. 2013 Clinical Neuroanatomy 27th ed. United States: McGraw-Hill Education, p.169-174; p. $277-279$.

[5] Mecarelli, O., Pro, S., Randi, F., Dispenza, S., Correnti, A., Pulitano, P., Vanacore, N., Vicenzini, E. and Toni, D., 2011. EEG patterns and epileptic seizures in acute phase stroke. Cerebrovascular Diseases, 31(2), pp.191-198.

[6] Feyissa, A.M., Hasan, T.F. and Meschia, J.F., 2019. Stroke-related epilepsy. European journal of neurology, $26(1)$, pp.18-e3.

[7] Debicki, D.B., 2017. Electroencephalography after a single unprovoked seizure. Seizure, 49, pp.69-73.

[8] Aminoff, MJ, Greenberg DA, Simon RP., 2015, 'Clinical neurology', 9th ed, Pennsylvania: McGraw-Hill Education, pp. 342-365.

[9] Mehndiratta, P., Wasay, M. and Mehndiratta, M.M., 2015. Implications of female sex on stroke risk factors, care, outcome and rehabilitation: an Asian perspective. Cerebrovascular Diseases, 39(5-6), pp.302-308.

[10] Zou, S., Wu, X., Zhu, B., Yu, J., Yang, B. and Shi, J., 2015. The pooled incidence of post-stroke seizure in 102008 patients. Topics in stroke rehabilitation, 22(6), pp.460-467.

[11] Zelano, J., Holtkamp, M., Agarwal, N., Lattanzi, S., Trinka, E. and Brigo, F., 2020. How to diagnose and treat post-stroke seizures and epilepsy. Epileptic Disorders, 22(3), pp.252-263.

[12] Conrad, J., Pawlowski, M., Dogan, M., Kovac, S., Ritter, M.A. and Evers, S., 2013. Seizures after cerebrovascular events: risk factors and clinical features. Seizure, 22(4), pp.275-282.

[13] Hundozi, Z., Shala, A., Boshnjaku, D., Bytyqi, S., Rrustemi, J., Rama, M. and Jashari, F., 2016. Hypertension on admission is associated with a lower risk of early seizures after stroke. Seizure, 36, pp.40-43.

[14] Tombeng, J.A., Mahama, C.N. and Kembuan, M.A., 2020. Profil Kejang Pascastroke pada Pasien Rawat Inap Periode Juli 2018-Juni 2019 di RSUP Prof. Dr. RD Kandou Manado. Medical Scope Journal, 1(2).

[15] Mehta, V. and Pujara, N., Assessment of Early Versus late Post Stroke Seizures and its Relationship with Different Risk Factors in Patients at bhuj, Kutch-A Cross-Sectional Study. Internation International Journal of Contemporary Medicine, p.45.

[16] Ahangar, A.A., Hosseini, S. and Saghebi, R., 2008. Clinical features of post stroke seizure in Babol, northern Iran. Neurosciences Journal, 13(1), pp.88-90.

[17] Guekht, A. and Bornstein, N.M., 2012. Seizures after stroke. In Handbook of clinical neurology (Vol. 108, pp. 569-583). Elsevier.

[18] Zhang, C., Wang, X., Wang, Y., Zhang, J.G., Hu, W., Ge, M., Zhang, K. and Shao, X., 2014. Risk factors for post-stroke seizures: a systematic review and meta-analysis. Epilepsy research, 108(10), pp.1806-1816.

[19] Doria, J.W. and Forgacs, P.B., 2019. Incidence, implications, and management of seizures following ischemic and hemorrhagic stroke. Current neurology and neuroscience reports, 19(7), pp.1-8.

[20] Procaccianti, G., Zaniboni, A., Rondelli, F., Crisci, M. and Sacquegna, T., 2012. Seizures in acute stroke: incidence, risk factors and prognosis. Neuroepidemiology, 39(1), pp.45-50.

[21] Panitchote, A. and Tiamkao, S., 2010. Prevalence of post-stroke seizures in Srinagarind Hospital. Medical journal of the Medical Association of Thailand, 93(9), p.1037.

[22] Meidiary, A.A.A., Gelgel, A.M. and Putra, I.G.N.P., Electroencephalogram (EEG) features and clinical presentation in the elderly patient at neurologic policlinic Sanglah General Hospital between July 2015-2017 period.

[23] Bentes, C., Martins, H., Peralta, A.R., Casimiro, C., Morgado, C., Franco, A.C., Fonseca, A.C., Geraldes, R., Canhão, P., e Melo, T.P. and Paiva, T., 2017. Post-stroke seizures are clinically underestimated. Journal of neurology, 264(9), pp.1978-1985.

[24] Sarecka-Hujar, B. and Kopyta, I., 2019. Poststroke epilepsy: current perspectives on diagnosis and treatment. Neuropsychiatric disease and treatment, 15, p.95.

[25] Kamble, S., Srivastava, T., Sardana, V., Maheshwari, D., Bhushan, B. and Ojha, P., 2017. Clinical and radiological profile of post stroke seizures. Ind J Neurosci, 3(1), pp.8-12.

[26] Siddiqi, S.A., Hashmi, M., Khan, F. and Siddiqui, K.A., 2011. Clinical spectrum of post-stroke seizures. J Coll Physicians Surg Pak, 21(4), pp.214-8.

[27] Okuda, S., Takano, S., Ueno, M., Hamaguchi, H. and Kanda, F., 2012. Clinical features of late-onset poststroke seizures. Journal of Stroke and Cerebrovascular Diseases, 21(7), pp.583-586.

[28] Misirli, H., Özge, A., Somay, G., Erdoğan, N., Erkal, H. and Erenoğlu, N.Y., 2006. Seizure development after stroke. International journal of clinical practice, 60(12), pp.1536-1541.

[29] Bladin, C.F. and Bornstein, N., 2008. Post-stroke seizures. Handbook of clinical neurology, 93, pp.613-621.

[30] Alberti, A., Paciaroni, M., Caso, V., Venti, M., Palmerini, F. and Agnelli, G., 2008. Early seizures in patients with acute stroke: frequency, predictive factors, and effect on clinical outcome. Vascular health and risk management, 4(3), p.715.

[31] Hameed, S., Hakeem, H. and Wasay, M., 2019. Post-stroke seizures: a clinically oriented Analysis. Pakistan Journal of Neurological Sciences (PJNS), 14(3), pp.21-26.

[32] Xu, M.Y., 2019. Poststroke seizure: optimising its management. Stroke and vascular neurology, 4(1). 
[33] Burneo, J.G., Fang, J., Saposnik, G. and Investigators of the Registry of the Canadian Stroke Network, 2010. Impact of seizures on morbidity and mortality after stroke: a Canadian multi-centre cohort study. European journal of neurology, 17(1), pp.52-58.

[34] Varelas, P.N. and Hacein-Bey, L., 2017. Ischemic Stroke, Hyperperfusion Syndrome, Cerebral Sinus Thrombosis, and Critical Care Seizures. In Seizures in Critical Care (pp. 155-186). Humana Press, Cham.

[35] Pezzini, A., Grassi, M., Del Zotto, E., Giossi, A., Volonghi, I., Costa, P., Poli, L., Morotti, A., Gamba, M., Ritelli, M. and Colombi, M., 2013. Complications of acute stroke and the occurrence of early seizures. Cerebrovascular Diseases, 35(5), pp.444-450.

[36] Chemer, N., \& Shevchenko, L. (2021). Post-stroke seizures: review article. INTERNATIONAL NEUROLOGICAL JOURNAL, 17(2), 16-20. https://doi.org/10.22141/2224-0713.17.2.2021.229889

[37] Camilo, O. and Goldstein, L.B., 2004. Seizures and epilepsy after ischemic stroke. Stroke, 35(7), pp.1769-1775.

[38] Chen, T.C., Chen, Y.Y., Cheng, P.Y. and Lai, C.H., 2012. The incidence rate of post-stroke epilepsy: a 5-year follow-up study in Taiwan. Epilepsy research, 102(3), pp.188-194.

[39] Serafini, A., Gigli, G.L., Gregoraci, G., Janes, F., Cancelli, I., Novello, S. and Valente, M., 2015. Are early seizures predictive of epilepsy after a stroke? Results of a population-based study. Neuroepidemiology, 45(1), pp.50-58.

[40] Wang, J.Z., Vyas, M.V., Saposnik, G. and Burneo, J.G., 2017. Incidence and management of seizures after ischemic stroke: systematic review and meta-analysis. Neurology, 89(12), pp.1220-1228.

[41] Chung, J.M., 2014. Seizures in the acute stroke setting. Neurological research, 36(5), pp.403-406.

[42] Smith, S.J., 2005. EEG in the diagnosis, classification, and management of patients with epilepsy. Journal of Neurology, Neurosurgery \& Psychiatry, 76(suppl 2), pp.ii2-ii7.

[43] Narayanan, J.T., Labar, D.R. and Schaul, N., 2008. Latency to first spike in the EEG of epilepsy patients. Seizure, 17(1), pp.34-41.

[44] Lüders, H. and Noachtar, S., 2000. Atlas and classification of electroencephalography. Saunders.

[45] Jaya, A.I., Soemarno, G. and Puspita, J.W., 2018, June. Classification of epileptiform waves based on frequency by using backpropagation neural network. In Journal of Physics: Conference Series (Vol. 1028, No. 1, p. 012048). IOP Publishing.

[46] Caplan, L.R. ed., 2016. Caplan's stroke. 5th ed. New York: Cambridge University Press, pp. 19-544 